\title{
A Task-Based Approach to Language Teaching: The Case for Task-Based Grammar Activities
}

\author{
María Rosario Cuesta Cuesta \\ Institute of Education, University of London
}

\begin{abstract}
Product and process approaches to the teaching of grammar have been enormously influential in language teaching. However, it would appear that not too strict an adherence to either product or process perspectives will prove satisfactory. In view of this, the issue is how to achieve a balance between a controlled approach to language development and the learners' direct involvement in the discourse process. The purpose of this paper is to explore ways of fashioning tasks in the classroom which control learner language while giving her opportunity for self-expression and creativity. The dangers of taking task-based teaching approaches to an extreme will also be analysed. The key with task-based learning is how to ensure a measure of regulation over learner activity, so that the acquisition of fluency is not developed at the expense of accuracy and interlanguage restructuring.
\end{abstract}

In recent years, some conception of task has been selected as the basic unit of analysis in different approaches and there has been a steady increase of interest in the use of taskbased alternatives to second language teaching. Three new, task-based syllabus types appeared in the 1980's. These are (1) the Procedural Syllabus, (2) the Process Syllabus, and (3) Task-Based Language Teaching. They are all analytic, type B syllabuses (for review, see White 44-112). With the adoption of task-based approaches, the emphasis is laid on learning processes rather than on the end products of these processes. Such approaches will be, therefore, means- rather than ends-based.

The term "task-based" certainly covers many different interpretations. So Long defines it as "a piece of work undertaken for oneself or for others, freely or for some reward. Thus, examples of tasks include painting a fence, dressing a child, filling out a form, buying a pair of shoes ... In other words, by 'task' is meant the hundred and one things people do in everyday life, at work, at play, and in between" ("Role for Instruction" 89). Richards, Platt and Platt offer the following definition: "an activity which is designed to help achieve a particular learning goal ... such as using the telephone to obtain information, drawing 
maps based on oral instructions. .." (373). In contrast, Candlin's emphasis on the learners' learning preferences (as opposed to the language or language learning processes) and his social and problem-solving orientation leads him to the following notion of task: "one of a set of differentiated, sequenceable, problem-posing activities involving learners and teachers in some joint selection from a range of varied cognitive and communicative procedures applied to existing and new knowledge in the collective exploration and pursuance of foreseen or emergent goals within a social milieu" ("Towards Task-Based Language Learning" 10). At the basis of Prabhu's definition, however, are tasks which engage the learner in thinking processes: "an activity which requires learners to arrive at an outcome from given information through some process of thought, and which allows teachers to control and regulate that process" (24).

Similarly, different approaches to the selection of tasks have been proposed. Thus Long (see Long, "Role for Instruction"; Crookes and Long, “Three Approaches"), who postulates a form of needs identification to be conducted as the starting point, considers the following steps for developing a task-based syllabus:

1. Conduct a needs analysis to obtain an inventory of target tasks.

2. Classify the target tasks into task types.

3. From the task types, derive pedagogical tasks.

4. Select and sequence the pedagogical tasks to form a task syllabus." ("Role for Instruction" 91)

Candlin ("Towards Task-Based Language Learning" 9-10), however, offers pedagogic criteria for judging the quality of what he calls "good" language learning tasks. An illustration of such criteria follows. He claims that good tasks should:

- promote attention to meaning, purpose, negotiation

- draw objectives from the communicative needs of learners

- involve language use in the solving of the task

- allow for co-evaluation by learner and teacher of the task and of the performance of the task

- promote a critical awareness about data and the processes of language learning.

In contrast, Prabhu points out that tasks should be selected and graded in terms of cognitive complexity. The examples of tasks include completing "whodunit" stories and answering questions about dialogues, calculating distances, giving directions, writing a curriculum vitae. Prabhu's approach lacks a needs identification. Activities are preset pedagogical tasks and are not linked up with a set of target tasks determined by an analysis of a particular group of learners' purposes. In this sense, "one possible criticism . . . is that no guidance is provided on the selection of problems and tasks, nor how these might relate to the real-world language needs of the learners. In other words, the focus is exclusively on learning processes and there is little or no attempt to relate these processes to outcomes" (Nunan, Syllabus Design 44). 
The rationale for task, as well as its definition, varies among different syllabus designers. But proponents of task as the organizational unit justify it especially on pedagogic and psycholinguistic grounds. Indeed, Long ("Task, Group") argues that taskbased approaches represent an advantage for those advocating an integrated approach to course design; they allow for information to be collected through needs analysis. Moreover, task-based approaches are compatible with communicatively oriented methodology. The development of Communicative Language Teaching has prompted a change in perspective in relation to the traditional distinction between methodology and syllabus design. Methodology becomes primary. In type B or analytic syllabuses, the syllabus is a set of methodological statements of how to teach and stimulate learning. In some process syllabuses, we only get a syllabus at the end as a record of what was done in the classroom. Some applied linguists even deny that process or task-based syllabuses are syllabuses at all, since the "what" and the "how" are intertwined. As Widdowson (120) points out, "the relevance of the syllabus has been redefined or called into question, even to the extent of denying the need for it altogether as a projected plan of work." In this sense, Candlin ("Syllabus Design" 35) suggests a "retrospective" syllabus, determined by the process of negotiation built into each component of the syllabus. Nunan argues that the separation of syllabus design and methodology becomes increasingly problematical with the use of tasks, since "one needs not only to specify both the content (or ends of learning) and the tasks (or means to those ends) but also to integrate them. This suggests a broad perspective on curriculum in which concurrent consideration is given to content, methodology and evaluation" (Designing Tasks 15).

Long also notes that materials involving tasks are "stimulating, intellectually challenging ... especially those of a problem-solving nature ... of a kind which seem meaningful to teachers planning and implementing lessons" ("Task, Group" 7). In other words, tasks are considered to be a more salient unit of planning for teachers than objectives. Further, such task-based approaches usually imply assessment of language achievement by means of criterion-referenced tests.

Breen and Candlin provide an educational and philosophical rather than a linguistic rationale for the Process Syllabus they have put forward. Thus, Candlin explains how educational goals can be made the focus of language learning tasks, and asserts that "targets for language learning are all too frequently set up externally to learners with little reference to the value of such targets in the general educational development of the learner. Because we are concerned with language learning, it is very easy to forget that we should be equally if not more concerned with the developing personalities of our learners" ("Towards Task-Based Language Learning" 16-17). There is a significant coincidence between Breen and Candlin's approach to education and progressivism, with their emphasis on exploration, growth and development. Breen and Candlin draw on Stenhouse's philosophy, associated with the Humanities Curriculum Project.

Task-based approaches, it is claimed, assume a model of language acquisition supported by research findings on language learning. The Process Syllabus shows direct influence from studies on the way learners approach learning. In comparison, the Procedural Syllabus, with its focus on the learners' cognitive processes, bases the rationale for its proposals on SLA theory and research. Following Krashen, Prabhu (70) maintains 
that linguistic structures are acquired subconsciously through "the operation of some internal system of abstract rules and principles" when the pedagogic focus is on task completion (i.e. meaning), instead of on the language used in the process. With regard to the kind of input learners were exposed to, this was mainly teacher talk (i.e. the language that teachers address to L2 learners, which is not always finely tuned to the level of the learner in the one-to-many classroom situation). In relation to errors, Prabhu (61) advocates "incidental," rather than "systematic" correction.

Task-Based Language Teaching incorporates findings from SLA research, most particularly studies exploring the effects of instruction and comparing classroom and naturalistic learning. Crookes and Long stress that the evidence of positive effects for instruction should lead teachers to use tasks and other pedagogic tools which draw learners' attention to features of the L2. As Crookes and Long (27) suggest, "when the task syllabus is combined with a focus on form in task-based language teaching, the task receives more support in SLA research as a viable unit around which to organize language teaching and learning opportunities."

All three approaches to syllabus design reject synthetic, type A syllabuses and linguistic elements (such as word, structure, notion or function) as the unit of analysis. In type A approaches, syllabus content is determined by an analysis of the language to be learnt. As Crookes and Long explain, "SLA research offers no evidence to suggest that nativelike exemplars of any of these synthetic units are meaningful acquisition units, that they are ... acquired separately, singly, in linear fashion, or that they can be learnt prior to and separate from language use" (34).

Parallelling the growing concern with the learner has been the reassessment of the role of error in both first and second language learning. Instead of being considered as deviations from the norms in traditional models, errors are now viewed by the abovementioned proposals for syllabus design as an integral part of the language learning process. Learners are constantly forming and reformulating hypotheses about the target language. This hypothesis-testing process seems to be the most relevant explanation of second language learning. When facing a problem in the target language, a L2 learner will infer from the $\mathrm{L} 1$ system and from her knowledge of $\mathrm{L} 2$. The potential errors resulting can be due to different reasons, and teachers should be aware of these processes when designing tasks. Apart from these psychological/cognitive factors, one can distinguish social/communicative reasons which may also account for errors. That is, learners are often encouraged to start using the language and concentrate on the communication of meanings, at the expense of accuracy. As Widdowson (111) summarizes, "errors have generally been attributed to cognitive causes, evidence of the learner's psychological process of rule formation. But they can also be seen as communicatively motivated, the realization of available resources to get a message across." One could argue that there is no easy solution to the problem of errors. However, attention has been paid to an area that had been previously neglected in language teaching. I would agree with those who demand more flexibility when considering errors at different stages in the learning process. In my opinion, teachers and learners will discuss in the classroom the difficulties that emerged from a specific activity and will try to compensate for them. 
Whether the focus is form, function or skills, product approaches segment the target language into discrete linguistic items for presentation one at a time. The assumption behind such approaches seems to be that language is analysable into a finite set of rules which can be combined in various ways to make meaning. Moreover, these approaches rely "on learners' assumed ability to learn a language in parts ... . which are independent of one another, and also to integrate, or synthesize, the pieces when the time comes to use them for communicative purposes" (Crookes and Long 28). Rutherford (4) calls this the "accumulated entities" view of language learning. Product approaches focus on what is to be learned (i.e. L2), on the knowledge and skills which learners should gain as a result of instruction.

Product approaches to grammar teaching obviously suffer from some problems, but they also have their strengths. Product approaches, it is argued, can facilitate the learning of grammar by providing opportunities for learners to notice and structure grammar. However, grammatical forms are unlikely to become internalized unless proceduralization can take place. Noticing and structuring grammar are not enough. This is where the third dimension of language learning comes in. Following Ellis (Understanding Language Acquisition), a distinction can be drawn between two types of L2 knowledge: declarative and procedural. The former refers to what the learner knows about the language, i.e. internalized L2 rules and memorized chunks of speech. The latter is "how to" knowledge; that is, it comprises "the strategies and procedures employed by the learner to process L2 data for acquisition and for use" (Ellis Understanding Language Acquisition 164). Proceduralizing refers to the mental organization of knowledge, so that accessing is made easy. Competent language users' knowledge of the language seems to be stored in the mind ready for use, already assembled for immediate access. This prefabricated speech has both the advantage of more efficient retrieval from memory and of permitting speakers to devote their attention to the larger structure of the discourse (see Bolinger and Pawley and Syder). In short, the mechanism of proceduralization "refers to the embedding of factual knowledge into productions so that the products of frequently executed productions can be retrieved directly from memory and declarative knowledge need not be activated in working memory for their execution" (Schmidt 363).

However, there is a second dimension which is sometimes referred to as "procedural skill" (Batstone, Schmidt). If proceduralized knowledge is concerned with the formation and storage of knowledge, procedural skill relates to the accessing and efficient performance in language use (e.g. being economical and avoiding undue repetition or excessive pausing, controlling pace, engaging strategies to be fluent). So learners need plenty of practice to proceduralize grammar in real-world language use. Without regular opportunities to put their grammar into action more or less automatically when negotiating meanings, much of the grammar learners may have noticed and structured through product work will gradually disappear. Furthermore, learners are likely to revert to a more lexical language system, which predisposes to fossilization and lack of intellectual development.

Therefore, grammatical forms will never become part of the learners' procedural knowledge unless they are encouraged to have access to their knowledge of the system in language use. So they will proceduralize a much richer system, encounter new language and stretch their own possibilities. In fact, requiring learners to engage in task-based 
grammar activities may well help them to use language creatively and develop the skills and strategies necessary to negotiate meanings in the discourse process. Tasks will be designed which will be concerned with language skills as real communication in real time, in the classroom. The emphasis will be on communication and the aim is to have learners communicate effectively.

Teachers, however, should be aware of the difficulty some learners find in learning to communicate in L2 and should also teach communication strategies, where learners are expected to paraphrase, borrow or invent words, use gesture, ask for feedback, simplify, etc. In this respect, Ellis (Understanding Language Acquisition) points out that language use involves, on the one hand, production and reception strategies and, on the other, communication strategies. Both native speakers and L2 learners use the same strategies, but they differ on the frequency. Production/reception strategies are concerned with the unproblematic use of the language and can be divided into planning and correcting strategies. In contrast, communication strategies can be defined, in Ellis' words, as follows: "Communication strategies are psycholinguistic plans which exist as part of the language user's communicative competence. They are potentially conscious and serve as substitutes for production plans which the learner is unable to implement" (Understanding Language Acquisition 182). Their main role is to keep the channel open in real communication situations. Ellis' typology of communication strategies includes reduction strategies (attempts to avoid the problem) and achievement strategies (aimed to overcome the problem, such as code-switching, literal translation, substitution, paraphrase, restructuring, etc.).

It can be argued that, with task-based approaches, learners are given the opportunity to practise all those strategies needed for productive language use and the negotiation of meaning. Likewise, learners are expected to develop the necessary skills for spoken interaction (e.g. how to turn take, hold or pass the floor, change the topic, enter and leave conversation, refuse without appearing rude). They are present in the conversational speech of most people and they are, in a sense, part of what makes conversation work. We recognize them as ways of negotiating the intricate business of social interaction via language. Research in this area of discourse has revealed different expectations of conversational interaction. This is especially relevant in ESL and EFL contexts, since culture-specific rules and mechanisms of, for example, turn-taking may bring about serious misunderstanding and breakdown of communication. The significance of a task-based approach for the learner in this area is considerable, as opposed to the traditional language classroom, "where turns are patiently organized and controlled by the teacher . . . Indeed the teacher who constantly interrupts the students' discourse to correct every grammatical mistake not only violates usual turn-taking procedures but may also hinder the students' acquisition of them" (Cook 57).

Communication, therefore, involves handling various aspects together, usually at high speed. Competent language users approach discourse in a top-down way and this is what a successful language learner must eventually be able to do. A distinction is usually drawn between two basic modes of information processing, which incorporate a balance between the degree of background knowledge or schema and the amount of language we need to bring to it. These are called bottom-up and top-down processing. Working under task- 
based conditions, learners are expected to gain control over the systems of language and communication operating as a whole. In other words, learners will find themselves interpreting discourse through top-down processing. Following Carrell and Eisterhold (557), "top-down processing . . . occurs as the system makes general predictions based on high level, general schemata and then searches the input for information to fit into these partially satisfied, higher order schemata. Top-down processing is, therefore, called "conceptually driven." In contrast, bottom-up processing interprets "the lowest-level units first, then proceeding to an interpretation of the rank above, and so on upwards" (Cook 156). Thus, bottom-up processing is "data driven" (Carrell and Eisterhold 557). Both modes of information processing occur at all levels simultaneously: it is again a matter of degree. The more familiar the general topic or situation, the less reliance needs to be placed on the language. Conversely, the less you can bring your existing knowledge of the world, the more you will need to attend to the text. In the former case, the tendency will be to process top-down (which is much more orientated towards schematic knowledge). In the latter, the reverse situation is found: your understanding will be given by attention to the systemic knowledge (i.e. bottom-up processing).

The top-down approach can be a very productive strategy for L2 learners. Yet textbooks have ignored top-down processing. As Cook (83) asserts, "a good deal of language teaching has followed a bottom-up approach, in that it has considered only the formal language system, often in isolated sentences, without demonstrating or developing the way that system operates in context." Textbooks do not usually build on the learners' personal knowledge. Learners are just given words and phrases to memorize, which leads them to a bottom-up approach to language. Communicative skills are widely assumed to be in a subsidiary position to language skills. Nevertheless, I would agree with Cook when he points out that "attention to discourse does not necessarily entail sacrificing the traditional emphasis on pronunciation and writing, grammar and vocabulary. These are essential elements in communication, and discourse is realized through them ... Discourse and formal skills are interdependent and must be developed together" (79).

The terms "top-down" and "bottom-up" are somewhat misleading, since they seem to trigger some kind of opposition. The difference, however, lies in the degree of conscious attention to language. It is again a dynamic continuum. In some situations, one will have to be more consciously aware of the language system than in others. But as I argue later, it is not always easy to get the balance between a top-down and a bottom-up approach.

It follows from the characterization of the task-based approaches proposed in the preceding part of this paper that grammar will emerge naturally out of communication in discourse. Rather than considering grammar as a static product, what we have here is a dynamic view of grammar. In Rutherford's words (57), “in one interpretation of the nature of language we have the 'machine' concept yielding a language 'product' whose prime manifestation is a language 'construct.' In our other ... interpretation we have the 'organism' concept embodying language processes among which is all-important 'grammaticization."' Grammar, therefore, has a side to it that can properly be called "organic." Learners are encouraged to call on grammar as a necessary resource for the creation of meanings in the discourse process. Similarly, Widdowson observes (97) that "language learning is essentially learning how grammar functions in the achievement of 
meaning." Hence the contribution of conversational interaction to SLA. Some researchers (see Hatch) point out the possibility that it is through participating in conversations in a L2 that one learns the L2 syntax. Grammar will evolve out of engagement in collaborative discourse. In this way, task-based grammar provides learners with a language-rich environment and recurring opportunities to notice, structure and proceduralize grammar in real-life language use.

It can be argued that these are the best conditions for grammar teaching. Our focus is to guide learners into self-expression without losing sight of the grammar. Unfortunately, there are reasons why this beneficial process might not be so certain to occur. The personal experience of countless teachers will show that learners tend to avoid any engagement with the language system when focusing on the negotiation of meaning. Instead, they seem to revert to lexis. As Skehan (205) puts it, "language users and learners bypass syntax and use lexical strategies to enable them to keep up with communication in real-time when constrained by a limited capacity information-processing system." Consequently, many learners fail to reach target language competence and fossilization may occur. Learners stay at the lexical stage, and proceduralize an extremely impoverished language system, which is grammatically fossilized, since they believe that they do not need to develop their interlanguage any further in order to communicate effectively whatever they want to. Thus, such learners may have procedural skill, but very little development of procedural knowledge. They may achieve fluency, but not accuracy. Skehan's article (205) is again relevant in this regard, expressing that task-based grammar "runs the risk of consolidating these pressures for lexicalised communication, and as a result will underplay the role of accuracy and of interlanguage restructuring."

This is the key issue connected with natural language use. Widdowson (163-64) summarizes his view in the following terms: "We do not want our learners to bypass language when they use it, as it is natural for native speakers to do, because they do not have the systemic knowledge as a backup resource to rely on. This is precisely what we want them to acquire and it is the purpose of pedagogy to assist them in acquiring it." In other words, native speakers are used to operating top-down. The emphasis is on paying as little attention as possible to language when they are dealing with something familiar. In a way, the systemic knowledge is put to the service of the schematic knowledge. But this is the danger: if a L2 learner interprets information through top-down processing, she may dispense with elements of grammar, as stated earlier, and fail to stretch her interlanguage. In contrast, we may find learners who are unwilling to take linguistic risks and are over-attentive to form. They are so cautious that they will never become fluent. These learners may have considerable procedural knowledge, but they cannot access that knowledge efficiently and automatically (i.e. they lack procedural skill).

In view of this, one might argue that the effectiveness of top-down processing has been overstressed, since it makes language to some extent redundant. The case for certain degrees of bottom-up processing may begin now. In my opinion, task-based grammar work should encourage learners to achieve both kinds of processing, and approach discourse in one way or the other depending on the specific circumstances.

Consequently, we will have to fashion our tasks very carefully. Learners may be given opportunities to use language in the task-based class. But unless regulated, learners will 
proceduralize a language system that is very reduced, and which may lead to fossilization and lack of interlanguage development. In Skehan's words, "requiring learners to engage in task-based learning may well, if not balanced by other activities, lead to the use of comprehension and communication strategies, and encourage a performance-oriented approach to learning, with the result that fluency and synthesis are developed at the expense of accuracy and restructuring" (196).

It follows from this that the key issue is to direct that proceduralization. This raises an important question for language teaching. How do we set up opportunities for language use in the classroom that take advantage of interaction, while at the same time they have an element of directioning, so that we can regulate learners' activity towards accuracy and fluency? The answer, once again, would lie in the achievement of balance between the competing requirements of both extremes. I would argue that there is a continuum in terms of teaching. In an extreme product approach, everything is under control, whereas in extreme process teaching, learners seem to have total initiative. In my opinion, neither extreme is satisfactory. We aim at a degree of balance: teachers can keep some control, while learners are using language in meaning-focused discourse. Learners are involved in tasks that direct them to negotiate meaning, that push them to create and take risks, while also encouraging them to work with grammar. As Batstone points out, these seem to be the ideal conditions for learners to notice, restructure and, particularly, proceduralize their grammar. In general terms, this is a position which is shared by a number of applied linguists, including Skehan, who concludes that "the key with task-based learning is how to preserve a controlled approach to language development, and ensure that the acquisition of fluency is not at the expense of development in structure" (197).

In this paper, I have sought to provide a rationale for a task-based approach to language teaching. Yet we have seen that there are dangers from taking such an approach in unrestrained form. In view of this, I have argued for the need of a judicious balance between the various goals in the teaching of grammar discussed earlier. If "the potential of task-based language teaching for harnessing instructional and learning strategies consistent with second language acquisition research findings" (Long, “Task, Group” 20) is to be realized, careful attention, I believe, should be paid to the issue of the regulation of learner language through task design.

\section{Works Cited}

Batstone, Rob. Grammar. Oxford: Oxford UP, 1994.

Bolinger, Dwight. "Meaning and Memory." Forum Linguisticum 1.1 (1976): 1-13.

Candlin, Christopher. "Syllabus Design as a Critical Process." General English Syllabus Design.

Ed. Christopher J. Brumfit. Oxford: Pergamon, 1984. 29-46. "Towards Task-Based Language Learning." Language Learning Tasks. Ed. Christopher

Candlin and Dermot F. Murphy. Englewood Cliffs: Prentice-Hall, 1987. 5-22. and David Nunan. Revised Syllabus Specifications for the Omani School English

Language Curriculum. Muscat: Ministry of Education and Youth, 1987. 
Carrell, Patricia L. and Joan C. Eisterhold. "Schema Theory and ESL Reading Pedagogy." TESOL Quarterly 17.4 (1983): 553-73.

Cook, Guy. Discourse. Oxford: Oxford UP, 1989.

Crookes, Graham, and Michael Long. "Three Approaches to Task-Based Syllabus Design." TESOL Quarterly 26.1 (1992): $27-47$.

Ellis, Rod. Instructed Second Language Acquisition: Learning in the Classroom. Oxford: Basil Blackwell, 1990. Understanding Language Acquisition. Oxford: Oxford UP, 1985.

Hatch, Evelyn Marcussen, ed. Second Language Acquisition: A Book of Readings. Rowley: Newbury House, 1978.

Krashen, Stephen. Principles and Practice in Second Language Acquisition. Oxford: Pergamon, 1982.

Larsen-Freeman, Diane, and Michael H. Long. An Introduction to Second Language Acquisition. London: Longman, 1990.

Long, Michael H. "A Role for Instruction in Second Language Acquisition: Task-Based Language Training." Modelling and Assessing Second Language Acquisition. Ed. Kenneth Hyltenstam and Manfred Pienemann. Clevedon: Multilingual Matters, 1985. 77-99.

"Task, Group, and Task-Group Interactions." University of Hawaii Working Papers in ESL 8.2 (1989): 1-26.

Nunan, David. Designing Tasks for the Communicative Classroom. Cambridge: Cambridge UP, 1989.

Syllabus Design. Oxford: Oxford UP, 1988.

Pawley, Andrew, and Frances H. Syder. "Two Puzzles for Linguistic Theory: Nativelike Selection and Nativelike Fluency." Language and Communication. Ed. Jack C. Richards and Richard W. Schmidt. London: Longman, 1983. 191-226.

Prabhu, N. S. Second Language Pedagogy: A Perspective. London: Oxford UP, 1987.

Richards, Jack C., John Platt and Heidi Platt, eds. The Longman Dictionary of Language Teaching and Applied Linguistics. Harlow: Longman, 1992.

Rutherford, William E. Second Language Grammar: Learning and Teaching. Harlow: Longman, 1987.

Schmidt, Richard. "Psychological Mechanisms Underlying Second Language Fluency." Studies in Second Language Acquisition 14.4 (1992): 357-85.

Skehan, Peter. "Second Language Acquisition Strategies and Task-Based Learning." Thames Valley University Working Papers in ELT 1 (1992): 178-208.

White, Ronald. The ELT Curriculum. Oxford: Basil Blackwell, 1988.

Widdowson, Henry G. Aspects of Language Teaching. Oxford: Oxford UP, 1990. 